\title{
Effects of Different Concentrations of Selenium on Antioxidant Enzyme Activity of Pterocypsela laciniata
}

\author{
Dandi Xu ${ }^{1, a}$, Yuzhi Wei ${ }^{1, b}$, Yue Gao ${ }^{1, c}$ Lijin Lin $^{2, d^{*}}$, Zitong Wang ${ }^{1, e}$ \\ and Yifei Zheng ${ }^{1, f}$ \\ ${ }^{1}$ College of Horticulture, Sichuan Agricultural University, Chengdu, Sichuan, China \\ ${ }^{2}$ Institute of Pomology and Olericulture, Sichuan Agricultural University, Chengdu, Sichuan, China \\ a2024286814@qq.com, b1203075091@qq.com, c2577934009@qq.com, dIlj800924@qq.com, \\ e94644103@qq.com, ${ }^{\mathrm{f}} 1092386434 @ q q . c o m$ \\ ${ }^{*}$ Corresponding author.
}

Keywords: Selenium; Pterocypsela laciniata; Antioxidant enzyme activity

Abstract: The effect of different selenium concentrations on the antioxidant enzyme activity of Pterocypsela laciniata was studied by pot experiment. The results showed that the effects of different selenium treatments on $P$. laciniata were significant. With the increase of selenium concentration, the trend of SOD, POD, CAT activities and soluble protein content showed a significant difference. When the concentration of selenium was $25 \mathrm{mg} \cdot \mathrm{kg}^{-1}$, the activities of SOD, POD and CAT of P. laciniata was the largest, and the content of soluble protein also reached the peak value. The results showed that selenium treatment could improve the activities of SOD, POD, CAT and soluble protein content of $P$. laciniata. When the selenium concentration was $25 \mathrm{mg} \cdot \mathrm{kg}^{-1}$, the effect was best.

\section{Introduction}

Adversity is a general term for all kinds of environmental factors that are harmful to plant growth and survival [1]. Under stress, the number of reactive oxygen species in plants increases dramatically, the activity of antioxidant enzymes in plants increases rapidly, and plays an important stress response to the scavenging of reactive oxygen species. It has become an important monitoring indicator of plant stress response under environmental stress [2]. Selenium is a necessary trace element for humans and animals. It has antioxidant functions in plants [3]. The study shows that selenium has a double effect on the organism, and the low concentration of selenium has antioxidation in the plant. When the concentration of selenium is too high, the activity of antioxidant enzymes is inhibited and selenium is toxic to plants [4-5].

Pterocypsela laciniata is a perennial herb of Pterocypsela. It not only has good flavor, delicate texture and high nutritional value, but also plays an important role in anti-tumor, anti-oxidation, anti-cardio cerebrovascular disease and so on. It can be used as a vegetable and can also serve as a good health care product for people [6]. Through agricultural bioaugmentation to obtain selenium enriched agricultural products is an effective way to supplement selenium for human body [7]. In this experiment, $P$. laciniata was cultivated in the soil containing different concentrations of selenium. The effects of different selenium concentrations on the activity of $P$. laciniata antioxidant enzyme were studied in order to find new selenium rich vegetables from wild vegetables and provide reference for the development of wild vegetables.

\section{Materials and Methods}

Materials. The seeds of $P$. laciniata were collected near the Chengdu Campus of Sichuan 
Agricultural University. After the seedling in the laboratory, at the end of March 2018, the seedlings with better growth and better consistency were transplanted to the pot.

Experimental Design. The soil was taken from the farmland soil near the Chengdu Campus of Sichuan Agricultural University. After the soil was dried, crushed and screened by $5 \mathrm{~mm}, 3.0 \mathrm{~kg}$ soil was put into the plastic basin of $15 \mathrm{~cm} \times 18 \mathrm{~cm}$ (high $\times$ diameter). Selenium is added to the soil in the form of $\mathrm{Na}_{2} \mathrm{SeO}_{3}$ solution and fully mixed. Keep the soil moist, place 60 days, mix the soil regularly and make the soil mix well. The selenium concentration in soil was $0,5,10,25,50,75$ and $100 \mathrm{mg} \cdot \mathrm{kg}^{-1}$ respectively. The seedlings were transplanted into the basin after breeding in the laboratory. 4 plants were planted in each pot, and four seedlings were scattered in the basin. Each treatment was planted with 6 pots ( 6 replicates). The distance between the basins is $10 \mathrm{~cm}$, and it is completely arranged at random. During the whole growth process of P. laciniata, water was kept daily to maintain the field capacity of about $80 \%$ of the soil in the basin and to remove other weeds and pests in time. After 50 days of cultivation, the young leaves of each P. laciniata were selected to determine their antioxidant enzyme activities. The content of soluble protein, the activity of POD, the activity of superoxide dismutase (SOD), and the activity of catalase (CAT) by ultraviolet spectrophotometry were determined by Coomassie brilliant blue G-250 method [8].

Statistical Analyses. Statistical analyses were conducted using statistical software of SPSS 17.0. Data were analyzed by one-way ANOVA with least significant difference at $5 \%$ confidence level.

\section{Results and Discussion}

POD Activity of $\boldsymbol{P}$. laciniata. The effect of selenium treatment on the POD activity of $P$. laciniata was significant (Fig. 1). With the increase of selenium concentration, the activity of POD first increased and then decreased. When the concentration of selenium was $25 \mathrm{mg} \cdot \mathrm{kg}^{-1}$, the activity of POD reached the peak. In the range of $5-75 \mathrm{mg} \cdot \mathrm{kg}^{-1}$, the activity of POD increased significantly, which was increased by $27.42 \%, 138.77 \%, 313.45 \%, 61.07 \%, 27.22 \%$, respectively. There was no significant difference in POD activity between $100 \mathrm{mg} \cdot \mathrm{kg}^{-1}$ and control group.

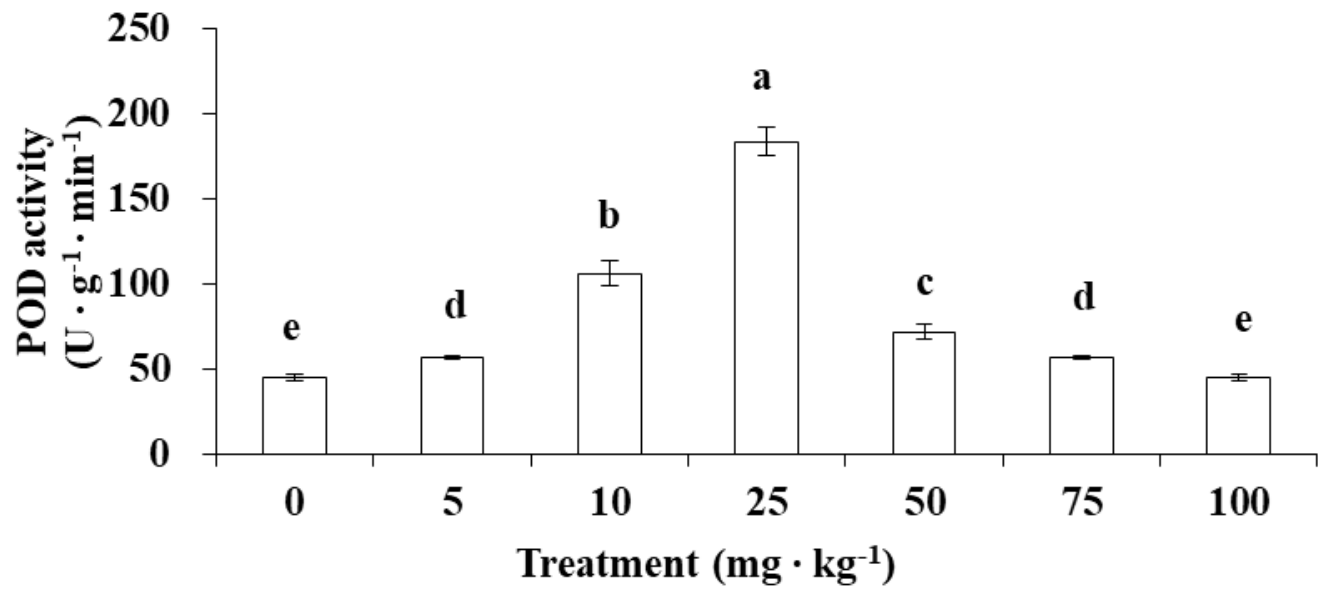

Fig. 1 POD activity of P. laciniata.

SOD Activity of $\boldsymbol{P}$. laciniata. With the increase of selenium concentration, the activity of SOD increased first and then decreased (Fig. 2). In the range of $5-25 \mathrm{mg} \cdot \mathrm{kg}^{-1}$, SOD activity increased by $5.33 \%, 6.73 \%, 7.71 \%$ compared with the control. In the range of selenium concentration 50-100 $\mathrm{mg} \cdot \mathrm{kg}^{-1}$, SOD activity decreased significantly compared with the control, decreased by $10.17 \%$, $25.55 \%, 38.17 \%$ respectively. 


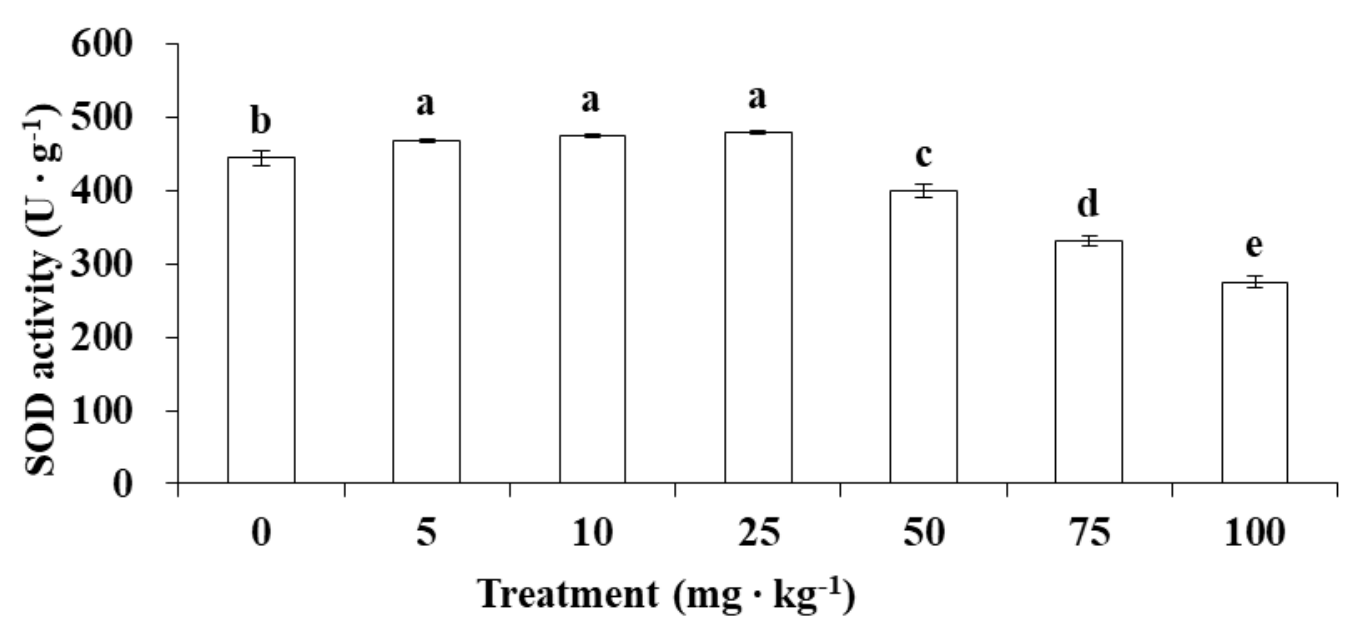

Fig. 2 SOD activity of $P$. laciniata.

CAT Activity of $\boldsymbol{P}$. laciniata. Under Se treatment, CAT activity was significantly different, and CAT activity increased first and then decreased (Fig. 3). When the concentration of selenium was 25 $\mathrm{mg} \cdot \mathrm{kg}^{-1}$, the activity of CAT was the highest. When selenium concentrations were $5,10,25$ and 50 $\mathrm{mg} \cdot \mathrm{kg}^{-1}$, CAT activity increased significantly compared with the control, increasing $23.03 \%$, $28.02 \%, 35.39 \%, 20.83 \%$, respectively. When the concentrations of selenium were 75 and 100 $\mathrm{mg} \cdot \mathrm{kg}^{-1}$, CAT activity decreased significantly compared with the control, decreased by $11.13 \%$ and $19.38 \%$.

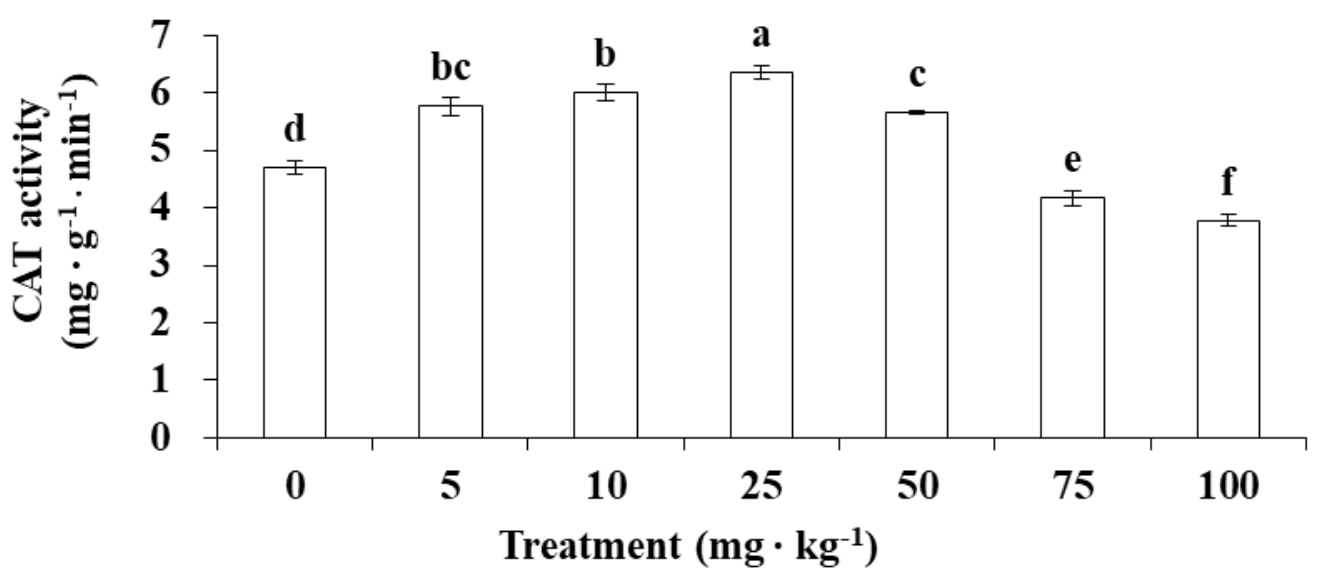

Fig. 3 CAT activity of P. laciniata.

Soluble Protein Content of $\boldsymbol{P}$. laciniata. With the increase of selenium concentration, soluble protein content first increased and then decreased (Fig. 4). When selenium concentrations were 5, 10 and $25 \mathrm{mg} \cdot \mathrm{kg}^{-1}$, the soluble protein content increased by $7.03 \%, 14.74 \%, 18.28 \%$ compared with the control. When Se concentration was $100 \mathrm{mg} \cdot \mathrm{kg}^{-1}$, the soluble protein content decreased by $28.71 \%$ compared with the control. The content of soluble protein in other treatments was not significantly different from that in the control group.

\section{Conclusions}

The effects of different selenium treatments on P. laciniata were significant. With the increase of selenium concentration, the trend of SOD, POD, CAT activities and soluble protein content showed a significant difference. When the concentration of selenium was $25 \mathrm{mg} \cdot \mathrm{kg}^{-1}$, the activities of SOD, 
POD and CAT of P. laciniata was the largest, and the content of soluble protein also reached the peak value. The results showed that selenium treatment could increase the activities of SOD, POD, CAT and soluble protein content of $P$. laciniata, when the concentration of selenium was $25 \mathrm{mg} \cdot \mathrm{kg}^{-1}$, the effect was the best.

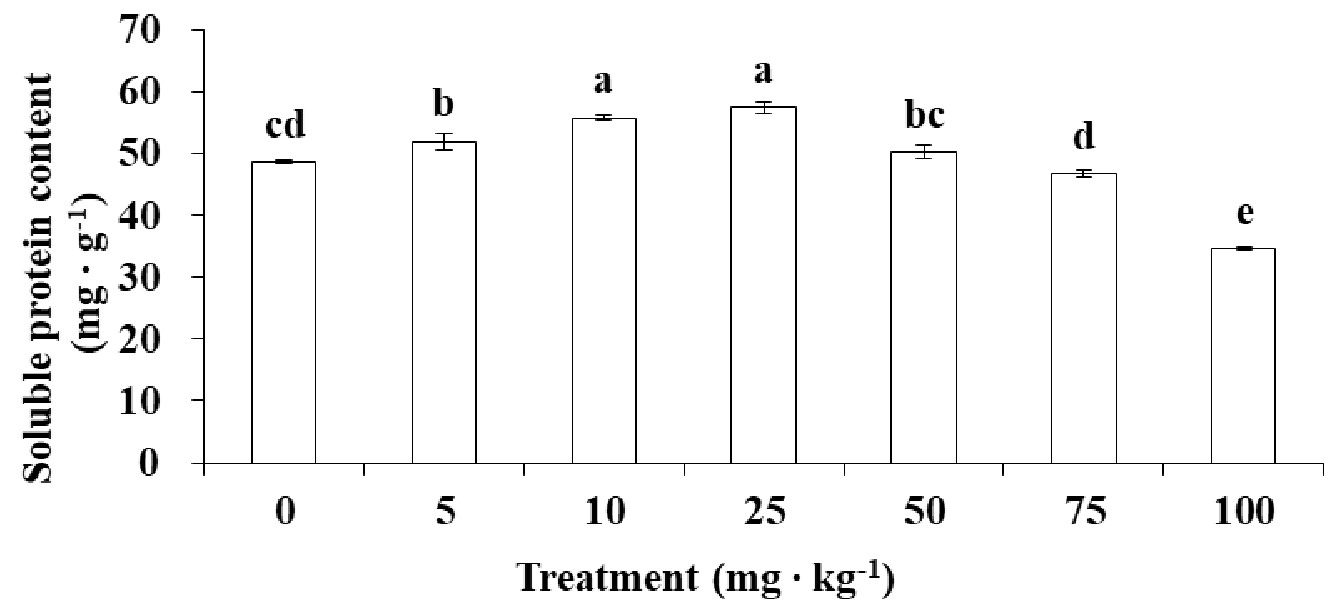

Fig. 4 Soluble protein content of P. laciniata

\section{Acknowledgements}

This work was financially supported by the Undergraduate Research Interests Training Program of Sichuan Agricultural University (2017).

\section{References}

[1] F.Y. Yu and X.Z. Xu: World Forestry Research Vol. 16 (2003), p. 6.

[2] X. Li, H. Yue, S. Wang, L.Q. Huang, J. Ma and L.P. Guo: China Journal of Chinese Materia Medica Vol. 38 (2013), p. 973.

[3] S.J. Chen, F. Yang, W.J. Zheng, Y. Bai, Z. Huang and Y.H. Zhou: Acta Hydrobiologica Sinica Vol. 31 (2007), p. 706.

[4] H. Xu and Y.N. Li: Jiangxi Acta Agriculturae Vol. 26 (2014), p. 63.

[5] H.L. Lei, X.L. Hu and Y.Y. Wu: Journal of Huazhong University of Science and Technology (Natural Science Edition) Vol. 38 (2010), p. 116.

[6] C.T. Hou, R.H. Wang, Y.Y. Zou, X.N. Song, H.X. Liu, F.H. Li and L.C. Xu: Food Science Vol. 34 (2013), p. 301.

[7] Rayman M P: British Journal of Nutrition Vol. 100 (2008), p. 254.

[8] Z.B. Hao, J. Cang and Z. Xu: Plant Physiology Experiment (Harbin Institute of Technology Press, Harbin, China 2004). 